\title{
SIGNIFICANCE OF RENAL FUNCTION IN TRAUMA: AN OBSERVATIONAL STUDY TO ASCERTAIN CORRELATION TO EGFR
}

\author{
Syed Faraz Anwar, Muhammad Uzair, Anas Bin Saif*, Ahmed Mushtaq Khan**, Saima Faraz \\ Combined Military Hospital Malir/National University of Medical Sciences (NUMS) Pakistan, *FTC Kotli/National University of Medical \\ Sciences (NUMS) Pakistan, ${ }^{* *}$ Combined Military Hospital Gujranwala/National University of Medical Sciences (NUMS) Pakistan
}

\section{ABSTRACT}

Objective: To assess renal function in patients at the time of arrival accident \& emergency of a tertiary care hospital.

Study Design: Retrospective observational study.

Place and Duration of Study: Tertiary care hospital, Karachi-Pakistan, from Oct 2015 to Oct 2018.

Methodology: All patients with major injuries (New Injury Severity Score NISS $\geq 16$ ) were included in the study to assess kidney function by calculating their estimated glomerular filtration rate (eGFR) using serum creatinine. Correlation was calculated between eGFR and other variables which were pulse, mean arterial pressure, temperature and haemoglobin.

Results: Seventy five patients were brought to accident and emergency. Fourteen (18.66\%) were brought in dead. There were $44(58.6 \%)$ gunshot wounds, 14 (18.6\%) blast injuries and $17(22.6 \%)$ accidents. Twenty six (34.66\%) were included in the study, with NISS $\geq 16$. All patients were male with mean age $29.73 \pm 5.08$. Twenty $(77 \%)$ patients were fluid resuscitated in pre-hospital setting whereas $6(23 \%)$ were not. Statistically significant correlations were found among eGFR and pulse rate, body temperature, mean arterial pressure, hemoglobin and NISS. Six out of 26 patients not resuscitated in pre-hospital setting had a median eGFR of 53.5, as compared to median eGFR of 70 in 20 patients who were resuscitated before evacuation in the field medical units.

Conclusion: Fluid resuscitation in the field lowers the possibility of renal dysfunction.

Keywords: Combat injuries, EGFR, Renal dysfunction. This is an Open Access article distributed under the terms of the Creative Commons Attribution License (http://creativecommons.org/licenses/by/4.0), which
permits unrestricted use, distribution, and reproduction in any medium, provided the original work is properly cited.

\section{INTRODUCTION}

Kidneys play a pivotal role of excretion in our body. In addition, it has been learnt rather recently that they have many endocrine functions as well making it one of the vital organs maintaining life. There are many tests to estimate the kidney functions but the most reliable is calculating glomerular filtration rate (GFR). However, it is a cumbersome process so it is evaluated by a formula to give estimated GFR (eGFR) which is reliable when age of patient is known ${ }^{1}$. Military soldiers are subject to harsh and rugged terrain throughout their service. There are no published reports of early estimates of renal dysfunction of combat soldiers evacuated from combat area in our country. Those who are affected, develop morbidity hence resulting in loss of useful manpower. There are many hazards to military

Correspondence: Dr Anas Bin Saif, Orthopedic Surgeon, Combined Military Hospital, Malir Karachi Pakistan

Received: 24 Mar 2019; revised received: 05 Aug 2019; accepted: 16 Aug 2019 deployment even before combat, like dealing with dangerous ammunition, environmental extremes, physical stresses, remote locations from medical and civic services, genetic lack of physiological reserve in deployed environment, medical evacuation issues, 2,3 . These are compounded by dehydration during operations. Therefore we not only require fit individuals with optimal physiological reserve but they need to have optimal medical support in combat, so as to re-engage them in an appropriate job as a useful soldier after they recover from trauma, depending on the disability. This course is significant because of high cost incurred in making and maintaining the personnel. Morbidity and mortality of a soldier in combat depends on many variables and one of them is renal function. A study done in Afghanistan showed that patients who suffered from Acute Kidney Injury due to combat related trauma have high mortality ${ }^{4}$. One study measured eGFR in trauma victims to assess renal 
function in the Emergency Department of field hospitals in Iraq and Afghanistan ${ }^{5}$. Another study of 751 multiple trauma victims ${ }^{6}$, did not have early estimates of renal function but did report that the probability of survival was less than 0.1 if peak serum creatinine exceeded $354 \mathrm{mM} / 1$ (eGFR $<20 \mathrm{ml} / \mathrm{min} / 1.73 \mathrm{~m}^{2}$ for a 25 year male Caucasian) any time in the post-traumatic period. Therefore it was decided to study the correlation between eGFR and other clinical and laboratory variables in our soldiers evacuated from combat area at the time of arrival in A \& E department. We wanted to know the significance of fluid resuscitation in pre hospital setting. eGFR calculation though, is not directly part of acute kidney injury (AKI) but mGFR (measured Glomerular Filtration Rate) is more accurate. This variable (eGFR) was selected due to lack of accurate record availability, as per AKI definition ${ }^{7}$. The most common shock inflicted upon soldiers is hypovolemia secondary to blood loss. Haemorrhagic shock, especially grade III and IV, reduces optimal blood pressure which leads to reduction in peripheral oxygen delivery to vital organs resulting in cascade of detrimental effects of which one can be Acute Kidney Injury. This reduction in glomerular filtration in turn definitely harbors widespread adverse effects. Therefore reduction in renal function could be related to changes in vital signs. If this correlation is ascertained then it would help the primary trauma physicians (regimental medical officers) in active combat to predict the fall in glomerular filtration rate and can respond optimally which would help improve the overall outcome.

\section{METHODOLOGY}

Accidental injuries were evacuated to Accident and Emergency (A \& E) of a tertiary care Combined Military Hospital, from October 2015 to October 2018. This was simple observational study of prospective analysis of retrospectively collected data. The required data was retrieved from clinical notes of patients from the statistics department of Combined Military Hospital through non-probability consecutive sampling technique. Sample size was calculated by using $\mathrm{WHO}$ online calculator keeping confidence level $=95 \%$ and confidence interval $=19.22$ and population size of 10000. Prior approval from ethics committee of hospital was taken. Patients with New Injury Severity Score (NISS) $\geq 16$ were included in the study. The NISS or ISS is an objective method of assessing the severity of trauma and is based on a scoring system where body is divided into six parts and injury to each part is graded from minor to non-survivable. A cumulative score of $>16$ is graded as severe injury or polytrauma ${ }^{8}$. All trauma victims with NISS $>16$ were excluded. Primary survey of patients was carried out by trauma team. Clinical and laboratory data for the study was collected by a doctors at A \& E. Clinical variables noted were pulse, mean arterial blood pressure, temperature at time of arrival at hospital and laboratory variables were serum creatinine, estimated glomerular filtration rate (eGFR) and haemoglobin. It is pertinent to mention here that the only the initial laboratory findings were noted. All the data was collected in a designated proforma. eGFR which is estimated GFR and is mathematically derived entity based on a patient's serum creatinine level, age, sex and race. This is calculated by the laboratory analyzing the blood sample and reported along with the serum creatinine result. CKD-Epi equation (Chronic Kidney Disease Epidemiology) is a recognized and well validated formula to calculate eGFR even for Asian population 9,10 . We calculated eGFR by the abbreviated CKD-Epi equation = $141 \times \min (\mathrm{Scr} / \mathrm{\kappa}, 1) \alpha \times \max (\mathrm{Scr} / \mathrm{\kappa}, 1)-1.209 \times 0.993$ age $\times 1.018$ if female $\times 1.159$ if black. We used online calculator to evaluate the eGFR. Blood pressure was converted to mean arterial pressure by formula, Mean Arterial Pressure $(\mathrm{MAP})=1 / 3$ (systolic-diastolic pressure) \pm dias-tolic pressure). As the variables did not follow a normal Gaussian curve so, medians along with ranges of all variables was recorded except age for which mean was used with standard deviation. Correlation co-efficient was calculated with Spearman correlation co-efficient using SPSS version 21. $p$ value of $<0.05$ was taken as significant keeping confidence interval of $95 \%$. 


\section{RESULTS}

Seventy five patients were brought to Accident \& Emergency. Fourteen (18.66\%) patients were brought in dead. There were 44 (58.6\%) gunshot wounds, 14 (18.66\%) blast injuries and 17 $(22.66 \%)$ accidents post ambush attack as shown in fig-1. The involvement according to body region is shown in fig- 2 . Twenty six $(34.66 \%)$ patients were included in the study, with NISS $\geq 16$. All patients were male and the mean age was $29.73 \pm 5.08$. Out of 26 patients included in study $20(77 \%)$ patients were fluid resuscitated in pre-hospital setting. Six (23\%) patients were not resuscitated in field either due to lack of medical

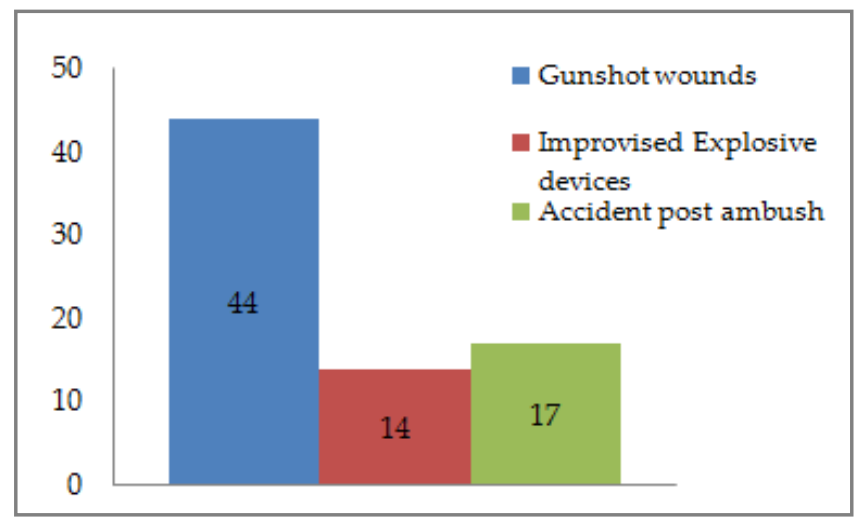

Figure-1: Mechanism of injury for 75 patients.

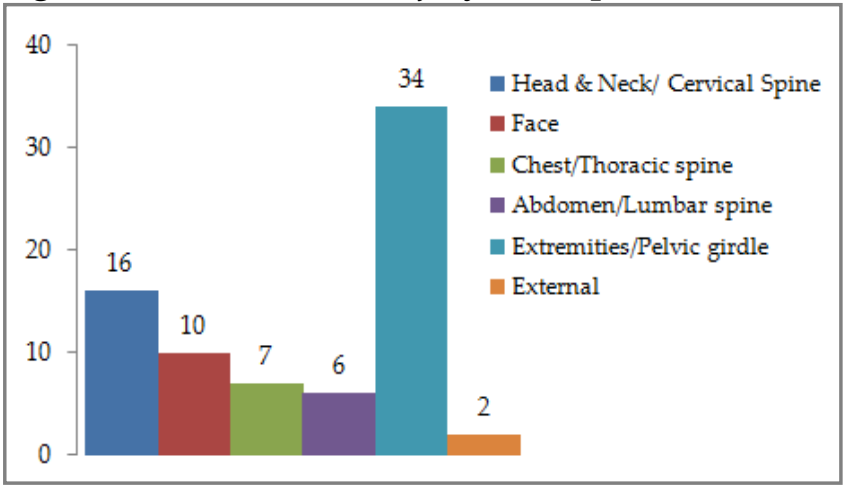

Figure-2: Body regions involved according to Injury Severitv Score for 75 patients.

services or rapid evacuation or may not have had an opportunity to reach to a nearest medical facility. For fluid resuscitation, Ringer's lactate was used in $12(60 \%)$ patients, isotonic saline in 4 $(20 \%)$ patients and blood in $4(20 \%)$ patients. The medians and ranges of eGFR, pulse, mean arterial pressure, Haemoglobin, temperature and NISS is shown in table-I. Statistically significant correla- tions were found among eGFR and pulse rate, correlation co-efficient $=-0.680(p$-value $<0.01)$, eGFR and mean arterial pressure, correlation coefficient $=0.698$ ( $p$-value $<0.01)$, eGFR and Haemoglobin, correlation co-efficient $=0.702(p$-value $<0.01$ ), eGFR and temperature, correlation coefficient $=0.643$ ( $p$-value $<0.01)$, eGFR and NISS, correlation co-efficient $=-0.823(p$-value $<0.01) .6$ out of 26 patients not fluid resuscitated in prehospital setting had a median eGFR of 53.50 $\mathrm{ml} / \mathrm{min} / 1.73 \mathrm{~m}^{2}$, as compared to median eGFR of $70 \mathrm{ml} / \mathrm{min} / 1.73 \mathrm{~m}^{2}$ in 20 patients who were administered fluid resuscitation before evacuation to $\mathrm{CMH}$ Malir, in the field medical units.

Table-I: Median values and ranges of variables.

\begin{tabular}{l|c|c}
\hline Variable & Median & $\begin{array}{c}\text { Interquartile } \\
\text { Range }\end{array}$ \\
\hline eGFR (ml/min/1.73m²) & 70 & 19 \\
\hline Pulse (beats/min) & 90 & 13 \\
\hline $\begin{array}{l}\text { Mean Arterial Pressure } \\
\text { (mmHg) }\end{array}$ & 87 & 10 \\
\hline Temperature (celsius) & 98 & 1 \\
\hline Hemoglobin (g/dl) & 12 & 5.2 \\
\hline $\begin{array}{l}\text { New Injury Severity } \\
\text { Score }\end{array}$ & 18 & 5 \\
\hline \multicolumn{2}{l|}{ eGFR, estimated glomerular filtration rate }
\end{tabular}

\section{DISCUSSION}

The exclusion of renal diseases in addition to other sickness is mandatory because adverse environment reduces renal reserve to a critical level, thus increasing susceptibility to trauma and infection. Water deprivation compounds the problem. Renal dysfunction potentially compromises not only the patient but also his comrades through reduced staffing and difficulty to execute the operation. They may become less responsible for the safety of weapons system. On border locations, need for evacuation may put aircraft or vehicles and their crew with medical attendants at unnecessary risk ${ }^{11,12}$. Since worldwide pre-hospital care has improved tremendously, the level of renal function on arrival in the Emergency Department has improved as well ${ }^{13}$. All of the available clinical evidence as observed in our study suggests that any serious reduction in the rate of oxygen delivery to the 
kidney or impaired oxygen utilization by the kidney results in deteriorating function manifesting as a falling glomerular filtration rate. The results in our study, though comprising only 26 patients are comparable to a foreign studies 4,14 . The foreign study was based on field hospitals in Iraq and Iran from 2005 to 2009. They retrospectively studied record of 287 military casualties with NISS $\geq 16$. Statistically significant correlations were found among eGFR and pulse rate $(\mathrm{r}=-0.3, p=0.0002)$, body temperature $(\mathrm{r}=0.24$, $p=0.01)$ and mean arterial pressure $(\mathrm{r}=0.2, p=0.02)$. The eGFR were better in those patients who had received pre hospital care in the forward field areas than those who did not. Optimal oxygen delivery is based on minimum $90 \mathrm{~mm} \mathrm{Hg}$ systolic and $60 \mathrm{~mm} \mathrm{Hg}$ of diastolic blood pressure. Rapid pulse (usually more than $100 \mathrm{bpm}$ ) indicates shock which reduces perfusion of organs. These were 2 important variables in our study. Therefore they were correlated with eGFR. At the same time, temperature also showed positive correlation which clearly indicates that hypothermia increases mortality ${ }^{15}$. Hypothermia induces coagulopathy, acidosis and cardiovascular, neurological, renal and hematologic effects; all contribute to increased morbidity and mortality ${ }^{16,17}$. Therefore it's not only the maintenance of blood pressure but temperature as well, in the pre hospital setting. This problem was identified in Iraq war in 2004 and beneficial remedial action was undertaken with a reduction in the frequency of hypothermia from $7 \%$ to $1 \%{ }^{18}$. The correlation with haemoglobin also reflected positively, indicating adequate perfusion is related to optimal haemoglobin concentration. There was also a statistically significant positive correlation between NISS and eGFR in our study which was not noted in previous researches ${ }^{4}$. As the severity of injury is increased there is proportionate loss of blood thus causing hypovolemia and there is subsequent strain on kidneys.

\section{LIMITATION OF STUDY}

This study has a limitation of the number of patients $(\mathrm{N}=26)$ which would be better explained if the study is conducted prospectively in a big- ger tertiary care hospital with high flow of trauma victims. In addition, the baseline pre-trauma creatinine and GFR of the patients were not known. However, our results does guide us on an important issue, pre-hospital resuscitation improves organ perfusion and reduces morbidity and mortality.

\section{ACKNOWLEDGEMENTS}

We are especially indebted to Dr Qasim Zaheer and Dr Umair Ahmed for the help and support. Moreover, the pathology department also assisted in providing prompt results of various laboratory parameters.

\section{CONCLUSION}

eGFR is good indicator of renal function. It has negative correlation with pulse and positive correlation with blood pressure, temperature and haemoglobin values. Thus tachycardia, low mean arterial pressure, hypothermia and reduced haemoglobin are indicators of reduced organ perfusion and herald renal dysfunction. Therefore pre-hospital fluid resuscitation before evacuation markedly reduces the chance of renal dysfunction.

\section{CONFLICT OF INTEREST}

This study has no conflict of interest to be declared by any author.

\section{REFERENCES}

1. Pottel H, Delanaye P, Weekers L, Selistre L, Goffin K, Gheysens $\mathrm{O}$, et al. Age-dependent reference intervals for estimated and measured glomerular filtration rate. Clinical kidney J 2017; 10(4): 545-51.

2. World MJ. Military nephrology-what a civilian doctor should know. Nephrol Dialy Transplant Plus 2011; 4(3): 153-57.

3. Stevenson T, Carr DJ, Penn-Barwell JG, Ringrose TJ, Stapley SA. The burden of gunshot wounding of UK military personnel in Iraq and Afghanistan from 2003-14. Injury 2018; 49(6): 1064-69.

4. Heegard KD, Stewart IJ, Cap AP, Sosnov JA, Kwan HK, Glass $\mathrm{KR}$, et al. Early acute kidney injury in military casualties. J Trauma Acute Care Surg 2015; 78(5): 988-93.

5. World MJ. Renal function after trauma. J R Army Med Corps 2013; 159(1): 94-97.

6. Sacco WJ, Long WB, Copes WS, Borzotta AP, Cardinal J, Coombes SS. Continuum of care trauma outcome evaluation. Socio-Economic Planning Sciences 1993; 27(3): 219-32.

7. Levey AS, James MT. Acute kidney injury. Annals Intern Med 2017; 167(9): ITC66-80.

8. DiMaggio C, Ayoung-Chee P, Shinseki M, Wilson C, Marshall G, Lee DC, et al. Traumatic injury in the United States: in-patient epidemiology 2000-2011. Injury 2016; 47(7): 1393-03. 
9. Matsushita K, Mahmoodi BK, Woodward M, Emberson JR, Jafar $\mathrm{TH}$, Jee $\mathrm{SH}$, et al. Comparison of risk prediction using the CKDEPI equation and the MDRD study equation for estimated glomerular filtration rate. Jama 2012; 307(18): 1941-51.

10. Ahmed S, Jafri L, Khan AH. Evaluation of'CKD-EPI Pakistan' quation for estimated glomerular filtration rate (eGFR): a comparison of eGFR prediction equations in Pakistani population. J Coll Phys Surg-Pak 2017; 27(7): 414-18.

11. Kotwal RS, Scott LL, Janak JC, Tarpey BW, Howard JT, Mazuchowski EL, et al. The effect of prehospital transport time, injury severity, and blood transfusion on survival of US military casualties in Iraq. J Traum Acut Care Surg 2018; 85(1S): S112-21.

12. Nerlander MP, Haweizy RM, Wahab MA, Älga A, von-Schreeb J. Epidemiology of trauma patients from the Mosul Offensive, 2016-2017: results from a dedicated trauma center in Erbil, Iraqi Kurdistan. World J Surg 2019; 43(2): 368-73.

13. Chung KK, Perkins RM, Oliver JD. Renal replacement therapy in support of combat operations. Crit Care Med 2008; 36 (7 Suppl): 365-69.
14. Jackson PC, Foster M, Fries A, Jeffery SL. Military trauma care in Birmingham: observational study of care requirements and resource utilization. Injury 2014; 45(1): 44-49.

15. Lapostolle F, Couvreur J, Koch FX, Savary D, Alhéritière A. Hypothermia in trauma victims at first arrival of ambulance personnel: an observational study with assessment of risk factors. Scand J Trauma Resusc Emerg Med 2017; 25(1): 43-48.

16. Perlman R, Callum J, Laflamme C, Tien H, Nascimento B, Beckett $\mathrm{A}$, et al. A recommended early goal-directed management guideline for the prevention of hypothermia-related transfusion, morbidity, and mortality in severely injured trauma patients. Crit Care Lond Engl 2016; 20(1): 107-10.

17. Kaafarani HMA, Velmahos GC. Damage control resuscitation in trauma. Scand J Surg SJS Off Organ Finn Surg Soc 2014; 103(2): 81-88.

18. Eastridge BJ, Jenkins D, Flaherty S, Henry S. Trauma system development in a theatre of war: Experiences from Operation Iraqi Freedom and Operation Enduring Freedom. J Trauma 2006; 61(6): 1366-72. 